\title{
Crustal thickening and rise of the Himalaya: A metamorphic perspective
}

\author{
JIA-MIN WANG $^{1}$, GAUTAM KHANAL ${ }^{1,2}$
}

${ }^{1}$ State Key Laboratory of Lithospheric Evolution, Institute of Geology and Geophysics, Chinese Academy of Sciences, Beijing 100029, China

${ }^{2}$ College of Earth and Planetary Sciences, University of Chinese Academy of Sciences, Beijing 100029, China

*J.-M. WANG: wangjiamin@mail.iggcas.ac.cn

Rise of the Himalaya and Tibetan Plateau has changed the climate of the Cenozoic Earth through underpining Asian monsoon and sinking atmospheric $\mathrm{CO}_{2}$. However, little is know when and how the proto-Himalaya mountains rose.

We applied petrochronology and phase equilibrium modelling to reveal main tectonometamorphic events across the Himalaya: 1) Migmatites from the Kathmandu Nappe with P-T of $\sim 730^{\circ} \mathrm{C}$ and $\sim 10.5 \mathrm{kbar}$, and peak metamorphic ages of 43-38 Ma shows that the Indian upper-crust sediments have been buried to anatecxic depth $(\sim 35 \mathrm{~km})$ shortly after initial India-Asia collision; 2) Eclogite enclosed by Greater Himalayan paragneiss from southern Tibet with peak P-T of $\sim 750^{\circ} \mathrm{C}$ and $\sim 20 \mathrm{kbar}$ and peak metamorphic ages of $\sim 30$ Ma shows that the Himalayan lower crust has been stacked full of metasediments to a thickness of 60-70 $\mathrm{km}$ during Oligocene; 3) Orogen-scale tectonometamorphic discontinuities/thrusts were prograting southward from hinterland to foreland (HHD 25-18 Ma, MCT 18-10 Ma and MBT $<10 \mathrm{Ma})$ to exhume the Himalayan Metamorphic core indicates intense crustal shortening during Miocene.

By combining these tectonometamorphic events with Himalayan Eocene shallow-sea basins, Miocene Siwalik foreland basins, and paleo-elevation data, we suggest that the Himalayan mountains 1) were initially uplifted to positive topography due to mid-Eocene crustal thickening, 2) reached significant high elevation as early as Oligcene to balance an over-thickened orogenic root, and 3) obtained its present elevation during Miocene due to orogen-scale thrustnappe tectonics. Our study suggests that rise of the Himalaya is dominated by crustal thickening instead of supplemental uplift after delamination and the Himalayan orogen has not yet collapsed to reach the end of the Welson cycle.

Note: This study was funded by the National Natural Science Foundation of China (41972065 and 41888101) 